\title{
Therapeutic efficacy of artemether-lumefantrine for Plasmodium vivax infections in a prospective study in Guyana
}

\author{
Daniel Eibach ${ }^{1,2^{*}}$, Nicolas Ceron ${ }^{3}$, Karanchand Krishnalall ${ }^{4}$, Keith Carter ${ }^{5}$, Guillaume Bonnot ${ }^{1}$, \\ Anne-Lise Bienvenu ${ }^{1}$ and Stéphane Picot ${ }^{1}$
}

\begin{abstract}
Background: In Guyana, chloroquine + primaquine is used for the treatment of vivax malaria. A worldwide increase of chloroquine resistance in Plasmodium vivax led to questioning of the current malaria treatment guidelines. A therapeutic efficacy study was conducted using artemether-lumefantrine + primaquine against $P$. vivax to evaluate a treatment alternative for chloroquine.

Methods: From 2009 to 2010, a non-controlled study in two hospitals in Guyana was conducted. A total 61 patients with $P$. vivax infection were treated with artemether-lumefantrine as a six-dose regimen twice a day for three days with additional $0.25 \mathrm{mg} / \mathrm{kg} / \mathrm{d}$ primaquine at day 0 for 14 days. Clinical and parasitological parameters were followed on days $0,1,2,3,7,14$ and 28 in agreement with WHO guidelines. Plasmodium vivax DNA from eight patients was analysed for pvmdr1, molecular marker of resistance.

Results: Artemether-lumefantrine cleared $100 \%$ of parasites on day 1, but two patients (3\%) had recurrence of parasites on day 28, suggesting relapse. No pvmdr1 Y976F polymorphism was detected. The treatment regimen was well tolerated.

Conclusions: In Guyana, artemether-lumefantrine represents an adequate treatment option against $P$. vivax when combined with primaquine. Availability of this alternative will be of great importance in case of emerging chloroquine resistance against $P$. vivax.
\end{abstract}

Keywords: Malaria, Plasmodium vivax, Artemether-lumefantrine, Chloroquine, Guyana

\section{Background}

Approximately 216 million malaria cases were reported world-wide in 2010 [1]. Outside of Africa, the most widely distributed species is Plasmodium vivax, followed by Plasmodium falciparum [1]. In South America, 1-1.2 million cases of malaria are reported annually with $P$. vivax responsible for three quarters and $P$. falciparum for one quarter of cases [2].

Artemisinin-based combination therapy (ACT) has been and still is one of the main pillars of the treatment

\footnotetext{
* Correspondence: daniel.eibach@chu-lyon.fr

'Malaria Research Unit, CNRS UMR 5246, University Lyon 1, Faculty of Medicine, Lyon, France

²European Public Health Microbiology Training Programme (EUPHEM), European Centre for Disease Prevention and Control (ECDC), Stockholm Sweden

Full list of author information is available at the end of the article
}

of malaria and is responsible for the reduction of malaria infections worldwide [3-7]. In recent years, reports from the border between Thailand and Cambodia [8,9] show resistance from $P$. falciparum to artemisinin-derivatives. Although in vitro resistance to artemether is reported for P. falciparum from South America [10], so far there is no evidence for treatment failures. Until now, only insufficient information on treatment outcomes with ACT for the treatment against $P$. vivax is available.

In Guyana, $42.3 \%$ of all malaria cases between 2005 and 2009 were caused by P. falciparum and $51.3 \%$ by $P$. vivax. The number of malaria cases declined rapidly until 2007 , but increased slightly in 2009 , with $93 \%$ of the population still being at risk of contracting malaria [1].

Anti-malarial drug policies in South American countries, including Guyana, use ACT for uncomplicated

\section{() Biomed Central}


$P$. falciparum and chloroquine + primaquine for $P$. vivax infections.

Chloroquine resistance against $P$. vivax was first reported in 1989 from Papua New Guinea [11]. Since then various countries, including Myanmar, Turkey, Ethiopia, Vietnam, Indonesia, Korea and Madagascar reported treatment failures with chloroquine [1,12-16]. Thailand reported its first chloroquine resistant $P$. vivax cases in 2011 [17], while in India chloroquine treatment seems still to be effective [18]. Reports from Colombia, Brazil, and Guyana [19] indicate chloroquine resistance appearing in numerous regions of South America [20,21].

This study aims to assess artemether-lumefantrine + primaquine as an alternative treatment option for $P$. vivax malaria, as a decline in susceptibility towards chloroquine can be predicted for the coming years. In the light of poor access to diagnostic facilities and emerging chloroquine resistance it is important to test the efficacy of artemether-lumefantrine as a common malaria treatment in Guyana. In remote areas, WHO recommends the use of rapid tests for malaria diagnosis. While several of these commercially available tests showed very good performances, their sensitivity and specificity for vivax Malaria is generally lower than for falciparum malaria. Since malaria species diagnosis could be uncertain, the issue of treatment efficacy of a single common treatment for all circulating plasmodium species had to be addressed.

Further the study aims to screen for $p v m d r 1$ singlenucleotide polymorphism at codon Y976F, suspected to be involved in $P$. vivax resistance to chloroquine [22].

\section{Methods}

Patient enrolment, treatment and follow-up procedures

A prospective multicentre study was conducted in 2009/ 2010 for artemether-lumefantrine + primaquine against $P$. vivax. Samples have been collected at two sites, the Malaria clinic Georgetown, situated in the administrative district 4 (Demerara-Mahaica; pop. 310.320), and at Port Kaituma Hospital in region 1 (Barima-Waini; pop. 24.275) of Guyana.

Included were all patients older than six month, weighing more than $10 \mathrm{~kg}$ and with a parasitological confirmed $P$. vivax mono-infection.

Patients were excluded from the study, if any of the following occurred: (i) presence of general danger signs in children aged under five years or signs of severe falciparum malaria according to the definitions of WHO [23], (ii) presence of severe malnutrition (defined as a child $<5$ years of age with a weight-for-height $\mathrm{z}$-score $<-3$, with symmetrical oedema involving at least the feet or with a mid-upper arm circumference $<110 \mathrm{~mm}$ ), (iii) history of hypersensitivity reactions or contraindications to any of the medications being tested, (iv) a positive pregnancy test or breastfeeding, (v) unable to or unwilling to take contraceptives, (vi) women between 12-26 years old in order to avoid potentially pregnant participants, (vii) use of anti-malarial drugs outside of the study protocol or regular medication, which may interfere with antimalarial pharmacokinetics, (viii) detection of mixed malarial infections during follow-up, (ix) presence of febrile conditions due to diseases other than malaria, (x) withdrawal of consent, (xi) loss to follow-up, (xii) protocol violation, or (xiii) death due to a non-malaria illness.

All study participants were treated with the treatment regimen used for $P$. falciparum infections, according to the national drug policy. They received artemetherlumefantrine (Novartis, batch number F1375, expiry date: 01.01 .2011 ) as a six-dose regimen twice a day for three days and additional $0.25 \mathrm{mg} / \mathrm{kg} / \mathrm{d}$ primaquine (NEW GPC INC Guyana, batch number B10392, expiry date 01.09.2011) for 14 days. The treatment dose was readministered, if patients vomited during 30 minutes after administration. Patients repeatedly vomiting after their first dose of study medication were excluded from the study. The three-day artemether-lumefantrine treatment was directly supervised on site, while the intake of primaquine was not directly observed. The study participants were not checked for glucose-6-phosphate dehydrogenase (G6PD) deficiency prior to primaquine administration, as its prevalence in Guyana is assumed to be low; however accurate information on this deficiency in Guyana is scarce. When participants presented symptoms of haemolytic anaemia (jaundice, dark urine, abdominal pain, back pain, lowered haemoglobin level) during the follow-up visits, the primaquine treatment had to be stopped and they were excluded from the study.

\section{Outcome measures}

Treatment outcomes were classified on the basis of the parasitological and clinical outcome according to the latest WHO guidelines [24], which classifies all patients as having early treatment failure, late clinical failure, late parasitological failure or an adequate clinical and parasitological response (ACPR). The ACPR was calculated for day 14 and day 28.

\section{Laboratory procedures}

Clinical examination, including measurement of the axillary temperature and Giemsa staining of thick and thin blood films, was carried out on days $0,1,2,3,7,14,21$, and 28. Thick and thin blood smears were prepared from finger sticks. After Giemsa staining, each slide was examined microscopically independently by two experienced technicians at the collection site and again at the Malaria Research Unit, University Lyon 1 . The parasitaemia was recorded as number of asexual parasites counted per 200 white blood cells present in the thick 
smear. The thick-film was considered to be negative, if no parasite had been found in 100 high-power fields. On days $0,7,14,21$ and 28 blood was blotted onto filter paper during follow-up and stored for DNA analysis.

\section{DNA extraction and amplification}

DNA was extracted from blood spots on filter paper with resin-based Instagene Matrix (Bio-Rad, Marnes la Coquette, France), as described before [25]. Genusspecific primers targeting the 18s rRNA were used to screen samples for the presence of Plasmodium. The identification of the parasite species was confirmed with species-specific primers (25), using LightCycler (Roche) real-time PCR. DNA was only available for a subset of eight $P$. vivax cases.

\section{Plasmodium vivax mdr1 gene}

Detection of SNPs in pvmdr1 (Y976F) was performed on the eight $P$. vivax cases using a LightCycler system (Roche) and fluorescence resonance energy transfer technology. Primers and probes were designed and synthesized by TIB Molbiol (DNA Synthesis Service, Berlin, Germany). The polymerase chain reaction mixture and assay conditions were used as described in detail elsewhere [22,26,27].

\section{Ethical approval}

The study protocol was reviewed and approved by the Ethics Committee of the Ministry of Health of Guyana. Informed written consent was provided by all patients or their parents/guardians before inclusion in the study.

\section{Results}

\section{Study population}

A total of 561 patients were screened for possible enrolment into the study and 74 (13.2\%) patients met the inclusion criteria. The Georgetown hospital contributed $87.8 \%(n=65)$ of patients, $12.2 \%(n=9)$ were recruited at the Port Kaituma Hospital. Among the patients included, 90.5\% were male, $9.5 \%$ female, with the majority of all participants (86.5\%) being between $15-49$ years old.

The different ethnicities of Guyana were representatively distributed with $47.3 \%$ from mixed ethnicities, 24.3\% East Indians, 16.2\% Amerindians, 10.8\% Afroguyanes and $1.4 \%$ of other groups. In total, $98 \%$ of the study population originated from the three highest malaria endemic regions 1,7 and 8 . The patients presented with the following symptoms in the preceding 24h: (i) Fever $20.3 \%$, (ii) vomiting $1.4 \%$, (iii) diarrhoea $2.8 \%$, (iv) problems with coordination $1.4 \%$, (v) dizziness or fainting $4.1 \%$. However the fever incidence will be underestimated due to frequent self-medication with antipyretic drugs. The mean parasitaemia counts were 3,920 parasites/ $\mu \mathrm{l}$ ranging from a maximum of 29,100 parasites/ $\mu \mathrm{l}$ to a minimum of 30 parasites/ $\mu \mathrm{l}$ (Table 1 ).
Table 1 Demographic, parasitological and clinical features of patients enrolled in the study

\begin{tabular}{|c|c|}
\hline & $n=74$ \\
\hline Age (median, range) & $24(5-57)$ \\
\hline Male/female & $67 / 7$ \\
\hline baseline parasitaemia (mean, range, $/ \mu \mathrm{l}$ ) & $3920(30-29100)$ \\
\hline \multicolumn{2}{|l|}{ baseline parasitaemia Group $(/ \mu \mathrm{l})$} \\
\hline $0-1000$ & $24(32.4 \%)$ \\
\hline $1000-10000$ & $44(59.5 \%)$ \\
\hline $10000-100000$ & $6(8.1 \%)$ \\
\hline$>100000$ & $0(0 \%)$ \\
\hline Baseline Temperature at admission (mean, range, ${ }^{\circ} \mathrm{C}$ ) & $36.6(36.0-39.2)$ \\
\hline Developed PV parasitaemia during follow-up & $2(2.7 \%)$ \\
\hline
\end{tabular}

Out of the 74 included patients, nine patients were lost for follow-up and four violated the protocol, resulting in 61 patients, which completed the study (Figure 1).

\section{Treatment study}

For all patients receiving treatment fever abated and parasites were cleared at day 1 . Two patients were found with parasitaemia at day 28 of the follow-up period, showing a parasite density of $487 / \mu \mathrm{l}$ and $780 / \mu \mathrm{l}$ respectively. The crude ACPR was $61 / 61$ (100\%) by day 14 , decreasing to $59 / 61$ (97\%) by day 28 . All patients tolerated the treatment well with very few side effects and no serious adverse events observed. No participants had to be excluded for haemolytic anaemia after primaquine administration.

In a subset of eight patients, the $P$. vivax mono-infection was PCR-confirmed. The others were microscopically confirmed by three independent readers. DNA from the parasites from the eight confirmed cases underwent screening for pvmdr1 single-nucleotide polymorphism at codon Y976F. No mutations were found.

\section{Discussion}

The study assessed artemether-lumefantrine + primaquine as a treatment option against $P$. vivax. Chloroquine and primaquine have been used worldwide against P. vivax as first-line drugs since 1946 and 1950 respectively. Reports from South-American countries such as Colombia and Brazil $[20,21]$ on decreasing chloroquine efficacy against $P$. vivax and a change of drug policies from chloroquine to ACT for vivax infections in four countries (Solomon Islands, Vanuatu, PNG and Papua (Indonesia)) [1], led to the question for an alternative treatment option in Guyana. So far only a few studies have examined artemether-lumefantrine as a treatment option for P. vivax and even less studies looked at artemether-lumefantrine and primaquine.

All patients in the study cleared parasites on day 1, which makes artemether-lumefantrine an efficacious 


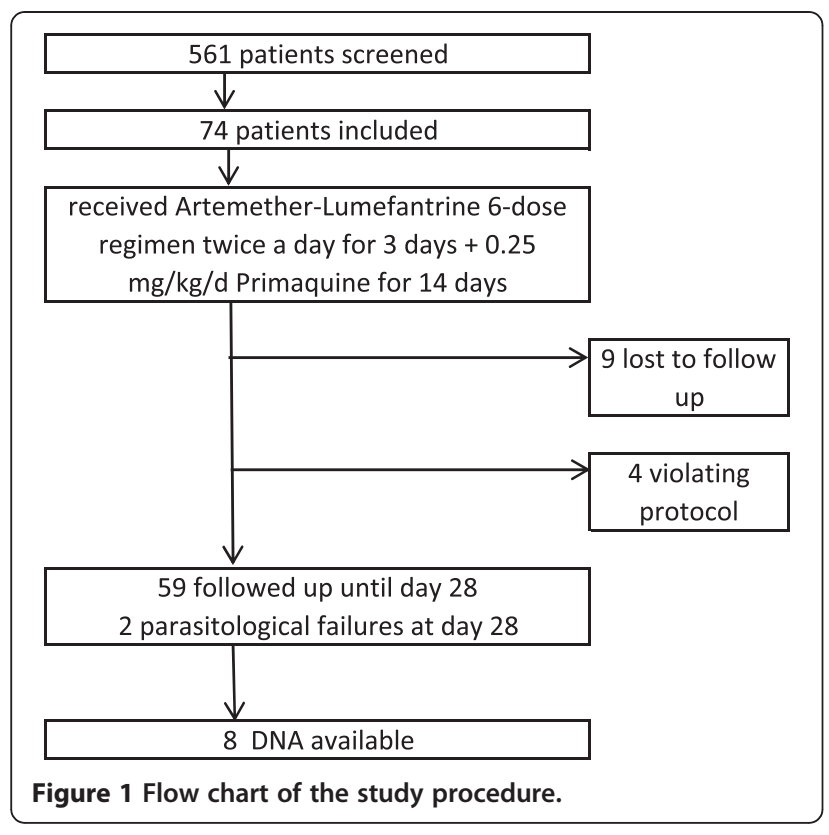

alternative for chloroquine in the treatment of vivax malaria. No severe side effects or adverse events were observed, similar to other studies, which show a good safety profile for artemether-lumefantrine alone [28-31] and for artemether-lumefantrine in combination with primaquine [30], when used for P. vivax infections. Drug interactions between the two drugs seem to be unlikely [32].

Two patients (2.7\%) presented with parasitological failure at day 28. In one of those patients $P$. vivax was PCR-confirmed at day 28 , with negative PCRs on day 7 , 14 and 21. It can be assumed that the new parasitaemia derived from relapse, rather than recrudescence, although a new infection or a recrudescence cannot be ruled out completely since there is no evidence that genotyping of $P$. vivax parasites may help to distinguish these events [33]. Frequent relapses with artemetherlumefantrine have been described, due to the short halflife of lumefantrine [28]. However, a combination with a longer-acting partner drug, such as piperaquine would only delay the $P$. vivax relapse, but not prevent it. Lumefantrine on the other hand is less likely to induce resistance compared to long half-life drugs as chloroquine or piperaquine [34]. In a situation, where primaquine can be administered in a safe and compliant manner, primaquine is the ideal drug for preventing relapse. However, a concerning rate of $24.5 \%$ resistance to primaquine has been described in Brazil [35], which could be one reason for the two treatment failures, observed in the study. Another reason might be a poor compliance to the unsupervised primaquine treatment.

With recent reports clearly demonstrating severe $P$. vivax infections resembling the course of malign $P$. falciparum infections [36,37] the application of a sufficient therapy has to be ensured. Therefore the continuing surveillance of chloroquine efficacy is of great importance. Studying the history of anti-malarial drug resistance development worldwide, it is not hard to predict that we also will encounter frequent treatment failures due to chloroquine in the upcoming years in South America.

A drawback to this study is that only eight patients could be screened for pvmdr1 single-nucleotide polymorphism and no mutations in codon Y976F were found. Low parasitaemia and sub-optimal sample storage conditions might partly explain the poor usefulness of the PCR method with these samples, while it usually works well with many other blood spot samples. No conclusions can be drawn on any resistance associated with $p v m d r 1$ polymorphism. One out of the two patients with treatment failure was tested for Y976F mutation, but was wild type. In total, $90 \%$ of the study participants were male. In Guyana, malaria affects many more males than females at a ratio of almost 4:1 (males $78.2 \%$ and females $21.8 \%$ ). This reflects the fact, that the migrant populations, primarily miners, are by far the most affected group. In addition to that all women aged 12 to 26 were excluded, in order to avoid potential pregnant study participants. $60 \%$ of all reported malaria cases occur in the Amerindian population, to which $16.2 \%$ of the study participants belong [38].

A switch of drug policies in Guyana to artemetherlumefantrine + primaquine for $P$. vivax infections would establish a common treatment for both circulating Plasmodium species, which are P. falciparum and $P$. vivax. Artemether-lumefantrine is highly effective against P. falciparum in Guyana, based on a study conducted in 2007/2008 (National Malaria Control Program, unpublished data). A common treatment could result in a number of advantages. Reports from Thailand and Indonesia detected up to $23 \%$ of $P$. falciparum infections being wrongly diagnosed as $P$. vivax, leading to inappropriate treatment with chloroquine $[39,40]$. ACT has also shown to clear P. vivax more quickly than chloroquine [41]. Treating $P$. falciparum with artemether-lumefantrine + primaquine would have the advantage of also treating potential dormant $P$. vivax hypnozoites, which are thought to become activated due to $P$. falciparum infections, thereby explaining the high number of vivax infections after P. falciparum treatment [33].

Keeping chloroquine in the market, could lead to its administration against $P$. falciparum in the private sector. Disadvantages of a common treatment will be the higher price for ACT as well as a decreased impetus for laboratories and hospitals in performing a correct plasmodium species diagnostic. The prescription of primaquine to all malaria cases without prior testing for G6PD deficiency presents a potential risk for severe haemolytic 
anaemia in G6PD-deficient patients, although G6PD deficiency is an infrequent trait in Guyana.

\section{Conclusions}

This study shows excellent efficacy for artemetherlumefantrine in combination with primaquine against $P$. vivax infections. The treatment efficacy for chloroquine for $P$. vivax must be under close surveillance in Guyana. Should resistance against $P$. vivax increase, the tested regimen with artemether-lumefantrine + primaquine will be a more than equal alternative and drug policies should be switched.

\section{Competing interests}

The authors declare that they have no competing interests.

\section{Authors' contributions}

DE contributed to molecular genetic studies, interpretation of results and the drafting of the manuscript. NC organized the collection of samples in

Guyana and helped with the interpretation of results. KK and KC contributed to the study design and the interpretation of results. GB generated a portion of the molecular data. ALB contributed to the interpretation of the data and writing of the manuscript. SP contributed to the study design, interpretation of results and the writing of the manuscript. All authors read and approved the final manuscript.

\section{Acknowledgements}

The authors would like to thank J.Thompson, C.David, N.Smith, H.Edghilo, L. Thomas, A.Maleaod, H.Khan, E.Bobb, W.Boyce, B.Noble and A.Lawrence for excellent technical assistance.

\section{Author details}

${ }^{1}$ Malaria Research Unit, CNRS UMR 5246, University Lyon 1, Faculty of Medicine, Lyon, France. ${ }^{2}$ European Public Health Microbiology Training Programme (EUPHEM), European Centre for Disease Prevention and Control (ECDC), Stockholm, Sweden. ${ }^{3}$ Pan-American Health Organization, Georgetown, Guyana. ${ }^{4}$ Vector Control Services, Malaria Control Programme, Ministry of Health Guyana, Georgetown, Guyana. ${ }^{5}$ Division of Disease Prevention and Control, Pan-American Health Organization, Washington, USA.

Received: 23 August 2012 Accepted: 18 October 2012

Published: 19 October 2012

\section{References}

1. World Health Organization: WHO Malaria Report.: World Health Organization; 2011.

2. Arevalo-Herrera M, Quiñones ML, Guerra C, Céspedes N, Giron S, Ahumada M, Piñeros JG, Padilla N, Terrientes Z, Rosas A, Padilla JC, Escalante AA, Beier $J$ C, Herrera S: Malaria in selected non-Amazonian countries of Latin America. Acta Trop 2011, 121:303-314.

3. Nosten F, van Vugt M, Price R, Luxemburger C, Thway KL, Brockman A McGready R, ter Kuile F, Looareesuwan S, White NJ: Effects of artesunate-mefloquine combination on incidence of Plasmodium falciparum malaria and mefloquine resistance in western Thailand: a prospective study. Lancet 2000, 356:297-302.

4. Barnes KI, Durrheim DN, Little F, Jackson A, Mehta U, Allen E, Dlamini SS, Tsoka J, Bredenkamp B, Mthembu DJ, White NJ, Sharp BL: Effect of artemether-lumefantrine policy and improved vector control on malaria burden in KwaZulu-Natal. South Africa. PLoS Med 2005, 2:e330.

5. Bhattarai A, Ali AS, Kachur SP, Mårtensson A, Abbas AK, Khatib R, Al-Mafazy AW, Ramsan M, Rotllant G, Gerstenmaier JF, Molteni F, Abdulla S, Montgomery SM, Kaneko A, Björkman A: Impact of artemisinin-based combination therapy and insecticide-treated nets on malaria burden in Zanzibar. PLoS Med 2007, 4:e309.

6. Carrara VI, Sirilak S, Thonglairuam J, Rojanawatsirivet C, Proux S, Gilbos V, Brockman A, Ashley EA, McGready R, Krudsood S, Leemingsawat $\mathrm{S}$, Looareesuwan S, Singhasivanon P, White N, Nosten F: Deployment of early diagnosis and mefloquine-artesunate treatment of falciparum malaria in Thailand: the Tak Malaria Initiative. PLOS Med 2006, 3:e183.

7. Price RN, Nosten F, Luxemburger C, ter Kuile FO, Paiphun L, Chongsuphajaisiddhi T, White NJ: Effects of artemisinin derivatives on malaria transmissibility. Lancet 1996, 347:1654-1658.

8. Noedl H, Se Y, Schaecher K, Smith BL, Socheat D, Fukuda MM: Evidence of artemisinin-resistant malaria in western Cambodia. N Engl J Med 2008, 359:2619-2620.

9. Dondorp AM, Nosten F, Yi P, Das D, Phyo AP, Tarning J, Lwin KM, Ariey F, Hanpithakpong W, Lee SJ, Ringwald P, Silamut K, Imwong M, Chotivanich K, Lim P, Herdman T, An SS, Yeung S, Singhasivanon P, Day NP, Lindegardh N, Socheat $\mathrm{D}$, White $\mathrm{NJ}$ : Artemisinin resistance in Plasmodium falciparum malaria. N Engl J Med 2009, 361:455-467.

10. Jambou R, Legrand E, Niang M, Khim N, Lim P, Volney B, Ekala MT, Bouchier C, Esterre P, Fandeur T, Mercereau-Puijalon O: Resistance of Plasmodium falciparum field isolates to in-vitro artemether and point mutations of the SERCA-type PfATPase6. Lancet 2005, 366:1960-1963.

11. Rieckmann $\mathrm{KH}$, Davis DR, Hutton DC: Plasmodium vivax resistance to chloroquine? Lancet 1989, 2:1183-1184

12. Baird JK: Resistance to therapies for infection by Plasmodium vivax. Clin Microbiol Rev 2009, 22:508-534.

13. Barnadas C, Ratsimbasoa A, Tichit M, Bouchier C, Jahevitra M, Picot S, Ménard D: Plasmodium vivax resistance to chloroquine in Madagascar: clinical efficacy and polymorphisms in pvmdr1 and pvcrt-o genes. Antimicrob Agents Chemother 2008, 52:4233-4240.

14. Sutanto I, Endawati D, Ling LH, Laihad F, Setiabudy R, Baird JK: Evaluation of chloroquine therapy for vivax and falciparum malaria in southern Sumatra, western Indonesia. Malar J 2010, 9:52

15. Guthmann JP, Pittet A, Lesage A, Imwong M, Lindegardh N, Min Lwin M, Zaw T, Annerberg A, de Radiguès X, Nosten F: Plasmodium vivax resistance to chloroquine in Dawei, southern Myanmar. Trop Med Int Health 2008, 13:91-98.

16. Kurcer MA, Simsek $Z$, Kurcer $Z$ : The decreasing efficacy of chloroquine in the treatment of Plasmodium vivax malaria, in Sanliurfa, south-eastern Turkey. Ann Trop Med Parasitol 2006, 100:109-113.

17. Rijken MJ, Boel ME, Russell B, Imwong M, Leimanis ML, Phyo AP, Muehlenbachs A, Lindegardh N, McGready R, Rénia L, Snounou G, Singhasivanon $\mathrm{P}$, Nosten F: Chloroquine resistant vivax malaria in a pregnant woman on the western border of Thailand. Malar J 2011, 10:113.

18. Srivastava HC, Yadav RS, Joshi H, Valecha N, Mallick PK, Prajapati SK, Dash AP: Therapeutic responses of Plasmodium vivax and $P$. falciparum to chloroquine, in an area of western India where $P$. vivax predominates. Ann Trop Med Parasitol 2008, 102:471-480.

19. Phillips EJ, Keystone JS, Kain KC: Failure of combined chloroquine and high-dose primaquine therapy for Plasmodium vivax malaria acquired in Guyana, South America. Clin Infect Dis 1996, 23:1171-1173.

20. de Santana Filho FS, Arcanjo AR, Chehuan YM, Costa MR, Martinez-Espinosa FE, Vieira JL, Barbosa MG, Alecrim WD, Alecrim MG: Chloroquine-resistant Plasmodium vivax, Brazilian Amazon. Emerg Infect Dis 2007, 13:1125-1126

21. Soto J, Toledo J, Gutierrez P, Luzz M, Llinas N, Cedeño N, Dunne M, Berman $\mathrm{J}$ : Plasmodium vivax clinically resistant to chloroquine in Colombia. Am J Trop Med Hyg 2001, 65:90-93.

22. Brega S, Meslin B, de Monbrison F, Severini C, Gradoni L, Udomsangpetch $R$, Sutanto I, Peyron F, Picot S: Identification of the Plasmodium vivax mdrlike gene (pvmdr1) and analysis of single-nucleotide polymorphisms among isolates from different areas of endemicity. J Infect Dis 2005, 191:272-277.

23. World Health Organization: Methods for surveillance of antimalarial drug efficacy. Geneva: World Health Organization; 2009.

24. World Health Organization: Monitoring Antimalarial Drug Resistance. WHO/CDC/CSR/EPH/2002.17. Geneva: World Health Organization; 2002.

25. de Monbrison F, Angei C, Staal A, Kaiser K, Picot S: Simultaneous identification of the four human Plasmodium species and quantification of Plasmodium DNA load in human blood by real-time polymerase chain reaction. Trans $R$ Soc Trop Med Hyg 2003, 97:387-390.

26. Brega S, de Monbrison F, Severini C, Udomsangpetch $R$, Sutanto I, Ruckert $P$, Peyron F, Picot S: Real-time PCR for dihydrofolate reductase gene single-nucleotide polymorphisms in Plasmodium vivax isolates. Antimicrob Agents Chemother 2004, 48:2581-2587. 
27. Marfurt J, de Monbrison F, Brega S, Barbollat L, Müller I, Sie A, Goroti M, Reeder JC, Beck HP, Picot S, Genton B: Molecular markers of in vivo Plasmodium vivax resistance to amodiaquine plus sulfadoxine-pyrimethamine: mutations in pvdhfr and pvmdr1. J Infect Dis 2008, 198:409-417.

28. Yohannes AM, Teklehaimanot A, Bergqvist $Y$, Ringwald P: Confirmed vivax resistance to chloroquine and effectiveness of artemether-lumefantrine for the treatment of vivax malaria in Ethiopia. Am J Trop Med Hyg 2011, 84:137-140

29. Pukrittayakamee S, Chantra A, Simpson JA, Vanijanonta S, Clemens R, Looareesuwan S, White NJ: Therapeutic responses to different antimalarial drugs in vivax malaria. Antimicrob Agents Chemother 2000, 44:1680-1685.

30. Krudsood S, Tangpukdee N, Muangnoicharoen S, Thanachartwet V, Luplertlop N, Srivilairit S, Wilairatana P, Kano S, Ringwald P, Looareesuwan S: Clinical efficacy of chloroquine versus artemether-lumefantrine for Plasmodium vivax treatment in Thailand. Korean J Parasitol 2007, 45:111-114.

31. Ratcliff A, Siswantoro H, Kenangalem E, Maristela R, Wuwung RM, Laihad F, Ebsworth EP, Anstey NM, Tjitra E, Price RN: Two fixed-dose artemisinin combinations for drug-resistant falciparum and vivax malaria in Papua, Indonesia: an open-label randomised comparison. Lancet 2007, 369:757-765.

32. $L i X Q$, Björkman $A$, Andersson TB, Gustafsson LL, Masimirembwa CM: Identification of human cytochrome $\mathrm{P}(450)$ s that metabolise anti-parasitic drugs and predictions of in vivo drug hepatic clearance from in vitro data. Eur I Clin Pharmacol 2003, 59:429-442.

33. Bassat $\mathrm{Q}:$ The use of artemether-lumefantrine for the treatment of uncomplicated Plasmodium vivax malaria. PLoS Negl Trop Dis 2011, 5:e1325

34. Douglas NM, Anstey NM, Angus BJ, Nosten F, Price RN: Artemisinin combination therapy for vivax malaria. Lancet Infect Dis 2010, 10:405-416.

35. Boulos M, Amato Neto V, Dutra AP, Di Santi SM, Shiroma M: Frequency of malaria relapse due to Plasmodium vivax in a non-endemic region (São Paulo, Brazil). Rev Inst Med Trop São Paulo 1991, 33:143-146.

36. Kochar DK, Das A, Kochar SK, Saxena V, Sirohi P, Garg S, Kochar A, Khatri MP, Gupta V: Severe Plasmodium vivax malaria: a report on serial cases from Bikaner in northwestern India. Am J Trop Med Hyg 2009, 80:194-198.

37. Price RN, Douglas NM, Anstey NM: New developments in Plasmodium vivax malaria: severe disease and the rise of chloroquine resistance. Curr Opin Infect Dis 2009, 22:430-435.

38. Pan American Health Organization: Guyana country cooperation strategy 2010-2015.: Pan American Health Organization; 2009.

39. Mayxay M, Pukritrayakamee S, Chotivanich K, Imwong M, Looareesuwan S, White NJ: Identification of cryptic coinfection with Plasmodium falciparum in patients presenting with vivax malaria. Am J Trop Med Hyg 2001, 65:588-592.

40. McKenzie FE, Sirichaisinthop J, Miller RS, Gasser RA Jr, Wongsrichanalai C: Dependence of malaria detection and species diagnosis by microscopy on parasite density. Am J Trop Med Hyg 2003, 69:372-376.

41. Silachamroon U, Krudsood S, Treeprasertsuk S, Wilairatana P, Chalearmrult K, Mint HY, Maneekan P, White NJ, Gourdeuk VR, Brittenham GM, Looareesuwan S: Clinical trial of oral artesunate with or without high-dose primaquine for the treatment of vivax malaria in Thailand. Am J Trop Med Hyg 2003, 69:14-18.

\section{Submit your next manuscript to BioMed Central and take full advantage of:}

- Convenient online submission

- Thorough peer review

- No space constraints or color figure charges

- Immediate publication on acceptance

- Inclusion in PubMed, CAS, Scopus and Google Scholar

- Research which is freely available for redistribution

Submit your manuscript at www.biomedcentral.com/submit
C Biomed Central 